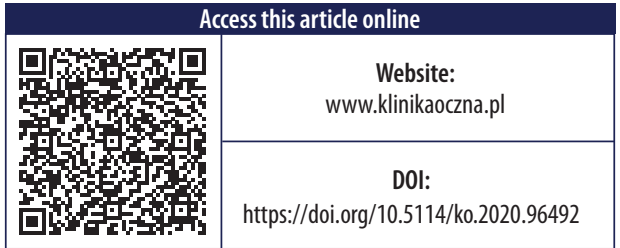

\title{
Eye health risks associated with the use of electronic devices and awareness of youth
}

\author{
Natalya Skoblina ${ }^{1}$, Andrei Shpakou ${ }^{2,3}$, Olga Milushkina' ${ }^{1}$, Svetlana Markelova ${ }^{1}$, Aleh Kuzniatsou ${ }^{2}$, Andrey Tatarinchik \\ 'Pirogov Russian National Research Medical University, Moscow, Russia \\ ${ }^{2}$ High Medical School in Bialystok, Bialystok, Poland \\ ${ }^{3}$ Yanka Kupala State University of Grodno, Grodno, Belarus
}

\begin{abstract}
Aim of the study: To investigate the awareness of schoolchildren and students about the risks of lack of hygienic skills of using electronic devices (ED) for the visual system and eye symptoms.

Material and methods: Quantitative indicators were calculated for assessing the impact of risk factors on the state of visual health of 768 schoolchildren and students from Russia and Belarus.

Results: The majority of respondents adequately assessed the risk of exposure to behavioral factors for health and eyesight. The majority of respondents rated their health as "good", a quarter of them as "satisfactory". Among respondents, vision was rated as "excellent" by 49 (24.5\%) and 147 (25.9\%), "good" by 53 (26.5\%) and 128 (22.5\%), "satisfactory" by $36(18.0 \%)$ and 152 (26.8\%), "poor" by $62(31.0 \%)$ and $141(24.8 \%)$ of schoolchildren and students,
\end{abstract}

respectively. The main sources of information about the problem of the organs of vision for respondents are the Internet (80\%), "parents" (60\%), "doctors" (43.0\% and 61.8\%), "teacher" $(36.0 \%$ and $61.4 \%)$.

Conclusions: Despite a fairly high level of knowledge about the negative impact on vision of irrational work with gadgets, the temptation to use them in adverse visual conditions does not decrease. In the group of schoolchildren, the risk indicator for health and eyesight is more pronounced: a careless attitude to their own health compared to students. University teachers should take into account the fact that students consider the opinion of teachers authoritative for the formation of health-saving competencies of youth.

KEY WORDS: health, students, eye symptoms, electronic devices.

\section{INTRODUCTION}

The world is ever changing due to advances in the realm of science and technology. One such advance is in the field of information and communication technology (ICT). ICT has become a standard fixture in the lives of many young people. In addition to the entertainment aspects, electronic devices (ED, gadgets) play an important part in the social lives of people [1]. In recent decades we have witnessed a sharp increase in the availability and use of personal electronic devices (digital devices) such as laptops and handheld computers, smartphones, and institution's computers, tablets and similar and associated devices [2-4]. The percentage of smartphone users - especially among minors - is growing, and there is growing literature suggesting increasing rates of problematic smartphone use in children and adolescents [5]. In the last decade Russians purchased about 400 million mobile means of communication [6], in 2019 - the record number of smartphones - 30.14 million pieces. Between 2011 and 2017, the use of smartphones by Russian teenagers increased from less than $20 \%$ to $80 \%$. More active ICT use may, however, affect the visual system and eye symptoms in a negative way. Many authors have reported the negative effects of overuse of electronic devices during education and leisure $[7,8]$. According to a survey conducted for the Vision Council 70\% of adults say they have experienced some of the symptoms of digital eye strain. It is becoming a widespread problem as more people spend hours each day looking at computers, cellphones, iPads, tablets and other electronic devices $[9,10]$. As a result, the decrease in vision limits actions, causes a feeling of being unwell, mood decline, and decreased mental performance and quality of life. The long-term ocular effects of smartphone and handheld digital device use are unknown. However, a range of short-term ocular surface discomfort, visual discomfort and asthenopic symptoms are reported with smartphones and tablets use [11, 12]. Ocular surface discomfort includes sore eyes, dryness, stinging, burning, itchiness and irritation. Visual discomfort and asthenopic symptoms include blurred vision, difficulty in refocusing 
between viewing distances, headache, eye strain and double vision $[13,14]$.

With the increasing popularity of electronic devices, youths spend significant time on smartphone and other ICT, thereby developing addictive tendencies. Research concludes that youths are not only addicted but are also developing significant behavioral problems and visual discomfort and symptoms owing to excessive electronic devices usage. All that staring from frequent phone use, computer use, and TV watching can lead to eye strain, a visual health issue that, when found in this context, is often called computer vision syndrome [15]. Symptoms reported by computer users are classified into internal ocular symptoms (strain and ache), external ocular symptoms (dryness, irritation, burning), visual symptoms (blur, double vision) and musculoskeletal symptoms (neck and shoulder pain) [16]. With the increased use of electronic devices with visual displays, computer vision syndrome is becoming a major public health issue [17].

The basic component of healthy lifestyle of youths is complying with hygiene principles of vision protection. In this connection it is necessary to study the awareness of basic principles of a healthy lifestyle among the youth [12, 18, 19]. These main principles are: good-health mindset, mastering the skills of a healthy lifestyle, positive habits, and compliance with hygiene standards for visual health [20]. Based on the widespread use of computer technology and mobile phones in young people and society, we expected high ownership of electronic devices. Further, the devices are expected to have major impacts on the student's life from different aspects.

The aim of the study was to investigate the awareness of schoolchildren and students about the risks of lack of hygienic skills of using electronic devices for the visual system and eye symptoms, and to analyze the factors influencing the health and eyesight in modern youth.

\section{Research questions}

Based on previously available literature data, the following questions were asked: What is the impact of the time spent using electronic devices on schoolchildren's and students' eye health, dependence and social behavior? What are the main sources of information about the impact of risk factors on health and eyesight?

\section{MATERIAL AND METHODS}

\section{Study design, setting and population}

Using Google Forms, an online survey of 200 schoolchildren of grades 9-10 (age 15-16 years) from general educational organizations, gymnasiums and lyceums was conducted. 568 students (age 17-21 years) were also surveyed: $73 \%$ studied in the field of healthcare and medical sciences, $20 \%$ studied in education and pedagogical sciences, and the rest studied in the field of mathematical and natural sciences. The respondents lived in Russia (Moscow and the Moscow Region, Samara, Arkhangelsk, Tomsk) and Belarus (Grodno).

In this research we showed that information and communication technologies (Internet resource) and the voluntary informed consent from respondents can be used instead of the traditional questioning with paper forms. For example, Google Forms can provide us with mechanisms to allow us to make different questionnaires. Data could be transformed into Excel or another database with the opportunities of analysis in different statistical programs. The benefit of internet questionnaires is a significant reduction in survey costs. The questionnaire was developed by teachers of the Department of Hygiene at the Pediatric Faculty of the N.I. Pirogov Federal State Autonomous Educational Establishment of Higher Education in the name of N. I. Pirogova of the Ministry of Health of Russia, with certificates of specialist "Hygienic education", "Hygiene of children and adolescents", "General hygiene". Respondents were asked questions of an evaluative nature: "Assess the degree of risk on health and eyesight.... The questions are related to a subjective assessment of the impact of risk factors on health and, in particular, the organ of vision and visual health. The total risk of exposure to the factor was assessed on a 10-degree numerical scale, where 1 meant weak intensity and 10 meant the highest intensity of the risk factor.

\section{Statistical analysis}

The statistical analysis was conducted with STATISTICA v. 13 software (StatSoft). The compliance of the obtained values with the law of the normal distribution of the variational series was evaluated. Normality of variable distribution was tested using the Shapiro-Wilk test. Quantitative data had a distribution that did not differ from normal - methods of parametric statistics were used. Comparison of the quantitative variable values in two groups was performed using Student's $t$-test. In order to identify differences and relationships between variables, the $\chi^{2}$ test was used [21]. Values with a probability of $p<0.05$ were considered statistically significant.

\section{Ethical considerations}

The study was carried out in accordance with the requirements of the 1975 Helsinki Declaration (as amended in 2000) [22]. The study did not infringe on human rights, did not endanger the respondents, met the requirements of biomedical ethics: reviewed and approved in accordance with the good clinical practice (GCP) rules by the Regional Committee for Medical and Health Research Ethics in Pirogov Russian National Research Medical University. All studies were carried out in compliance with the ethical standards [23].

\section{RESULTS}

Interviewed groups of schoolchildren and students did not have significant gender differences. 146 (73\%) of the respondents from school and 431 (75.9\%) from university were girls (Pearson $\chi^{2}$ test $=0.7, p>0.1$ ). The groups of respondents did not have significant differences, as they subjectively assessed their state of health and their vision health. 105 (52.5\%) pupils rated their health as "good", 44 (22.0\%) as "satisfactory". 306 (53.9\%) students rated their health as "good", $161(28.3 \%)$ as "satisfactory" (Pearson $\chi^{2}$ test $=6.9$, $p>0.05)$ (Figure 1). 


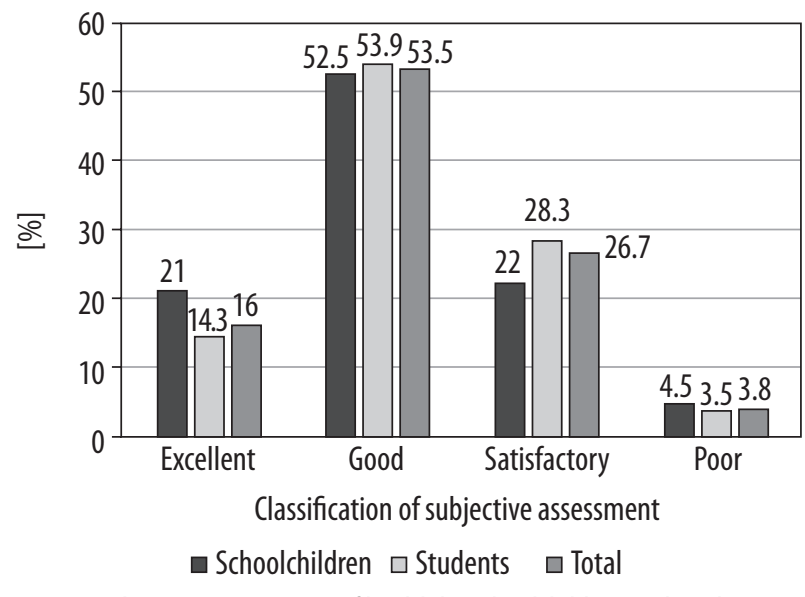

Figure 1. Subjective assessment of health by schoolchildren and students

Among schoolchildren, eye health was rated as "excellent" by 49 (24.5\%), "good" by $53(26.5 \%)$, "satisfactory" by $36(18.0 \%)$, "poor" by $62(31.0 \%)$; among students $147(25.9 \%), 128(22.5 \%), 152(26.8 \%)$ and 141 (24.8\%), respectively (Figure 2).

$98.9 \%$ of schoolchildren and students use electronic devices daily. 420 respondents (54.7\%) in both groups use a smartphone player or other electronic device with headphones daily. The average time spent in front of a device per day was between 4 and $5 \mathrm{~h}$.

Average values for assessing the impact of risk factors indicate that older schoolchildren and students adequately assess the risk of exposure to behavioral factors for health (Table I).

For respondents "an adequate assessment of the risk of exposure to a factor" was 5-7 points; for students 6-8 points. For factors affecting the organ of vision, the degree of health risk when working with electronic devices has been established: in low light conditions only 26 (13.0\%) schoolchildren and $72(12.7 \%)$ students are ready to abstain from work until returning to a well-lit place. Work in an unsuitable place (armchair, bed, on the floor, etc.) is chosen by $114(57.0 \%)$ schoolchildren and 304 (53.5\%) students. Work without interruption for 2 hours or more - 55 (27.5\%) and 147 (25.9\%); usually rest periods when working with electronic devices

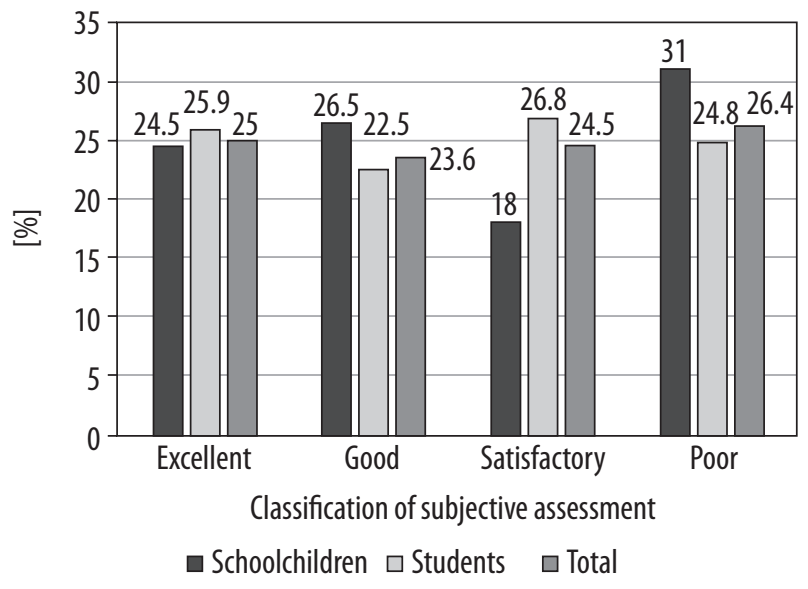

Figure 2. Subjective assessment of eye health by schoolchildren and students

are not used $-45(22.5 \%)$ and $96(16.9 \%)$, respectively. There were no statistically significant differences between groups.

Respondents were asked questions characterizing the practical skills of lifestyle and eye protection. To the question "Do you often take breaks to relax when working with electronic devices?" 39 (19.5\%) schoolchildren stated that they take a break every 30-40 minutes, which is consistent with the hygienic principles of vision protection. This indicator among students is 137 (24.1\%). 48 (24.0\%) and 105 (18.5\%) respondents, respectively, do not take breaks when working with electronic devices.

If it is necessary to work with electronic devices in a darkened room, only 26 (13.0\%) schoolchildren will refrain from working, which is consistent with the hygienic principles of vision protection. 74 (37.0\%) will continue to work in any conditions. $34(17.0 \%)$ of schoolchildren can use electronic devices while lying down and $80(40.0 \%)$ while sitting on the bed. $72(12.7 \%)$ students will refrain from working if it is necessary to work with electronic devices in a darkened room. 214 (37.9\%) will continue to work in any conditions. $264(46.5 \%)$ students working with electronic devices work at an organized workplace. The rest can use electronic devices while lying down (113; 19.9\%) and sitting on the bed (191; $33.6 \%)$; no significant differences between groups.

Table I. Assessment by schoolchildren and students of the impact of risk factors on health status, in points (M $\pm S D$ )

\begin{tabular}{|l|c|c|}
\hline Questions about the degree of risk of the impact of risk factors on health & \multicolumn{2}{|c|}{ Answers of } \\
\cline { 2 - 3 } & schoolchildren & \multicolumn{1}{c|}{ students } \\
\hline $\begin{array}{l}\text { Assess the health risk of working with electronic devices in low light conditions (dark time/twilight, in poor } \\
\text { quality lighting) }\end{array}$ & $6.21 \pm 2.32$ & $6.89 \pm 2.06^{*}$ \\
\hline $\begin{array}{l}\text { Assess the degree of risk to the health of working with electronic devices in an unsuitable place (armchair, bed, } \\
\text { on the floor, etc.) }\end{array}$ & $5.09 \pm 2.56$ & $6.08 \pm 2.46^{*}$ \\
\hline Assess the risk to the health of working with electronic devices without interruption for 2 hours or more & $6.40 \pm 2.43$ & $7.24 \pm 2.11^{*}$ \\
\hline Evaluate the degree of risk for sight of frequent and prolonged use of electronic devices & $6.36 \pm 2.74$ & $7.06 \pm 2.33^{*}$ \\
\hline Assess the risk to health of a lack of regular exercise and other physical activity (less than 2 hours per week) & $6.60 \pm 2.46$ & $7.09 \pm 2.13^{*}$ \\
\hline Assess the health risk of a sleep duration of less than 7-8 hours & $5.91 \pm 2.49$ & $6.58 \pm 2.34^{*}$ \\
\hline Total risk & $5.48 \pm 1.44$ & $6.11 \pm 1.30^{*}$ \\
\hline
\end{tabular}

$M-$ mean, SD - standard deviation. ${ }^{*}$ statistical significance $(p \leq 0.05)$ 
Table II. Characteristics (assessment) of the dependence of health of the vision and the use of glasses, in \% (95\% Cl)

\begin{tabular}{|l|c|c|c|c|}
$\begin{array}{l}\text { Subjective assessment } \\
\text { of vision health }\end{array}$ & $\begin{array}{c}\text { I do not need vision } \\
\text { correction }\end{array}$ & $\begin{array}{c}\text { Ineed vision correction, but } \\
\text { I don't use glasses }\end{array}$ & $\begin{array}{c}\text { I use glasses specially selected for working } \\
\text { with electronic devices }\end{array}$ & $\begin{array}{c}\text { I use ordinary } \\
\text { glasses }\end{array}$ \\
\hline Excellent & 100 & 0 & 0 & 0 \\
\hline Good & $73.0(66.6-79.4)$ & $14.6(9.5-19.7)$ & $5.4(2.2-8.7)$ & $7.0(3.4-10.7)$ \\
\hline Satisfactory & $17.6(12.1-23.0)$ & $39.9(32.9-46.9)$ & $4.3(1.4-7.2)$ & $38.3(31.4-45.3)$ \\
\hline Poor & $5.4(2.3-8.5)$ & $28.1(21.9-34.3)$ & $7.9(4.2-11.6)$ & $58.6(51.8-65.4)$ \\
\hline Total & $48.3(44.8-51.8)$ & $20.7(17.8-23.6)$ & $4.4(3.0-5.9)$ & $26.6(23.4-29.7)$ \\
\hline
\end{tabular}

95\%(1 - 95-percent confidence interval

$88(44.0 \%)$ schoolchildren answered that they do not need vision correction - they are schoolchildren who rated their vision as "excellent" and "good". 239 (42.1\%) students replied that they did not need vision correction. When working with electronic devices, 11 (5.5\%) pupils and $23(4.0 \%)$ students surveyed use specially selected glasses, 37 (18.5\%) and $122(21.5 \%)$ do not use glasses, but they require vision correction (they use glasses selected "for distance") and $54(27.0 \%)$ and $150(26.4 \%)$ use ordinary glasses, respectively. Thus, nearly $40 \%$ of schoolchildren and students do not adhere to the principles of vision protection in life. The risk group of schoolchildren and students who rated their eyesight as "poor" was determined $(68 ; 33.5 \%)$, and when questioned, they answered that "vision correction is not needed" (11; 5.4\%), "I need vision correction, but I don't use glasses" (57; 28.1\%) (Table II).

The main sources of information on preventive measures for the protection of vision for schoolchildren are information from the Internet - 158 (79.0\%), information from "parents, relatives" - 111 (55.5\%), "medical professional” - 86 (43.0\%) and "teacher" - 72 (36.0\%). $22(11.0 \%)$ respondents are not interested this topic and problem. The main sources of information for students are the Internet - 503 (88.6\%), "medical professional" - 351 (61.8\%), "teacher" - 349 (61.4\%), "parents and relatives" - $342(60.2 \%)$, and 20 (3.5\%) respondents are not interested in this topic and problem (Figure 3 ).

\section{DISCUSSION}

The modern education system is a "risk zone" due to the intensity of the educational process, which is accompanied by stresses (mental), decreased physical activity, and disturbances in sleep and rest. The learning process is characterized by dynamism, high labor intensity, a variety of forms and methods of training, an increase in the amount of information, and the introduction of new training tools and technologies, which requires additional reserves from the body [24, 25]. An urgent problem of modern public health is the increasing activity of the use of ED, gadgets and, as a result, the increase in negative effects on the organ of vision under their influence. Children and adolescents are growing up exposed to modern information and communication technology. Studies have shown such modern technologies as smartphones, tablets, and computers that have been developed and become increasingly widespread over the past decade to be beneficial and to constitute health risks for youth [26]. An awareness of the basics of a healthy lifestyle and the hygienic principles of vision protection was shown by more than $50 \%$ of schoolchildren and students. Respondents adequately assessed the risk of behavioral factors affecting health and visual health. Everyone who spends a lot of time behind the screen of telephone displays, tablets and computers is prone to computer vision syndrome. Schoolchildren and students experience a variety of ocular symptoms related to computer use, such as redness, blurred vision, double vision, eye strain - symptoms of computer vision syndrome $[27,28]$. The results of studies on the health status of schoolchildren and university students have shown a steady negative trend towards an increase in diseases caused by the influence of educational environment factors. There is an increase in functional disorders and chronic diseases of the body systems (musculoskeletal, digestive, nervous, visual organs) acquired in the learning process [25]. Health disorders acquired during school years are exacerbated during continuing education at university [18]. A lot of youth face eye problems when they sit in front of a television or a laptop screen for hours on end. In addition to this, eye strain can lead to eye fatigue, blurry vision, and focus issues, which can be very irritating and dangerous. Authors have stated the negative effect of overuse of electronic devices during education and leisure $[29,30]$. In our study, mobile phones, smartphones and laptops were the gadgets most frequently used by respondents. Vision was considered "excel-

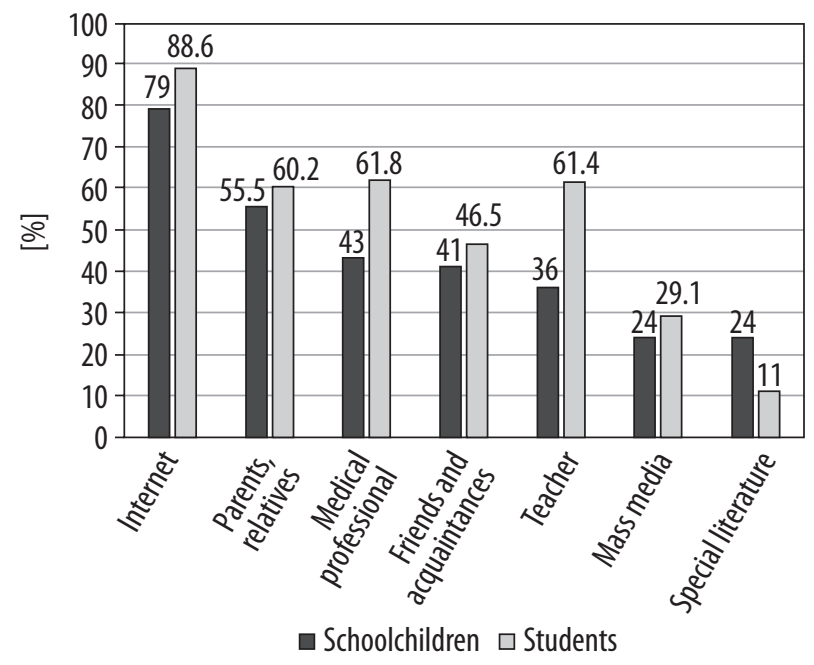

Figure 3. The main sources of information about the eyesight problem 
lent" by $25.9 \%$ of respondents, "good" by $22.5 \%$, "satisfactory" by $26.8 \%$ and "bad" by $24.8 \%$. Using gadgets for a long time can produce symptoms of computer vision syndrome. The average time spent in front of a device per day was between 4 and 5 hours. When using mobile phones and laptops with an average use of 1 to 4 hours per day, subjective signs were distinguished: blurred vision, headache and stuffy eyes [28]. The authors of this study indicate that visual complaints were reported by $75 \%$ of the users who work for more than 5 hours [28]. The results of the study connect long-term work with a computer display and the accelerated development of symptoms such as burning sensation and foreign body, diplopia, and myopia [29].

The negative trends in the state of the organ of vision among schoolchildren and students and the negative trends in lifestyle revealed in the study require training in healthy lifestyle skills in educational institutions. The role of the teacher in this process is significant. As preventive hygiene measures to protect eyesight, it is recommended to use electronic devices only in places with a good level of illumination, including artificial ones, with continuous use of no more than $60 \mathrm{~min}$, using glasses if necessary and correcting vision. It is necessary to expand the knowledge of these population groups on healthy lifestyle issues and motivate them to use knowledge in professional activities and everyday life.

This study employed a large, well-defined populationbased sample of youth. This sample had a limited age range. The data employed in this study are from a recent data collec- tion. The cross-sectional design of this study precluded any causal inference.

\section{CONCLUSIONS}

The results of the assessment of the (subjective) awareness of schoolchildren and students about the consequences of the irrational use of electronic devices and the hygienic principles of vision protection indicated that more than half of the respondents adequately assessed the risk of exposure to behavioral factors on health and the organ of vision. Despite a fairly high level of knowledge about the negative impact on vision of irrational work with gadgets, the temptation to use them in adverse visual conditions does not decrease. In the group of schoolchildren, the risk indicator for health and functional disorders of the organ of vision is more pronounced: a careless attitude to their own health compared to students.

More than half of schoolchildren perceive parents, medical workers and friends as "sources" of information about a healthy lifestyle. Almost two thirds of students perceive health workers, teachers and parents as the "source" of information about a healthy lifestyle. University teachers should take into account the fact that students consider the opinion of teachers authoritative for the formation of health-saving competencies of youth.

\section{DISCLOSURE}

The authors declare no conflict of interest.

\section{References}

1. Soni R, Upadhyay R, Jain M. Prevalence of smart phone addiction, sleep quality and associated behaviour problems in adolescents. Int J Res Med Sci 2017; 5: 515-519.

2. Statista. Number of smartphone users worldwide from 2014 to 2020 (in billions). 2019. Available from: https://www.statista. com/ statistics/330695/number-of-smartphone-usersworldwide/ (cited: 18 March 2020).

3. Thomée S, Dellve L, Harenstam A, et al. Perceived connections between information and communication technology use and mental symptoms among young adults - a qualitative study. BMC Public Health 2010; 10: 1-14.

4. Chesley N. Information and communication technology use, work intensification and employee strain and distress. Work Employment Society 2014; 28: 589-610.

5. Fischer-Grote L, Kothgassner OD, Felnhofer A. Risk factors for problematic smartphone use in children and adolescents: a review of existing literature. Neuropsychiatr 2019; 33: 179-190.

6. Experts have calculated how much Russians spent on the purchase of mobile phones in 10 years [Eksperty poschitali, skol'ko potratili rossiyane na pokupku mobil'nykh telefonov za 10 let] (serial online), 28 Jan 2020 (cited 5 March 2020). Available from: https:// tass.ru/ekonomika/7624515 (in Russian).

7. Smahel D, Wright M, Cernikova M. The impact of digital media on health: children's perspectives. Int J Public Health 2015; 60: 131-137.

8. van der Lely S, Frey S, Garbazza C, Wirz-Justice A, et al. Blue blocker glasses as a countermeasure for alerting effects of evening light-emitting diode screen exposure in male teenagers. J Adolesc Health 2015; 56: 113-119.

9. Alfahad FN. Effectiveness of using information technology in higher education in Saudi Arabia. Proc Soc Behav Sci 2012; 46: 1268-1278.

10. Eyes overexposed: the digital device dilemma. Available at: https://visionimpactinstitute.org/wp-content/uploads/2016/03/2016 EyeStrain_Report_WEB.pdf (cited 18 March 2020).

11. Moon JH, Kim KW, Moon NJ. Smartphone use is a risk factor for pediatric dry eye disease according to region and age: a case control study. BMC Ophthalmol 2016; 16: 188.

12. Kim DJ, Lim C, Gu N, et al. Visual fatigue induced by viewing a tablet computer with a high-resolution display. Korean J Ophthalmol 2017; 31: 388-393.

13. Jaiswal S, Asper L, Long J, et al. Ocular and visual discomfort associated with smartphones, tablets and computers: what we do and do not know. Clin Exp Optom 2019; 102: 463-477.

14. Antona B, Barrio AR, Gascó A, et al. Symptoms associated with reading from a smartphone in conditions of light and dark. Appl Ergon 2018; 68: 12-17.

15. Klamm J, Tarnow KG. Computer vision syndrome: A review of literature. Medsurg Nurs 2015; 24: 89-93.

16. Gowrisankaran S, Sheedy JE. Computer vision syndrome: A review. Work 2015; 52: 303-314. 
17. Randolph SA. Computer vision syndrome. Workplace Health Saf 2017; 65: 328.

18. Skoblina NA, Milushkina OY, Obrubov SA, et al. Hygienic factors in formation of functional deviations and chronic eye diseases for schoolchildren and students under current conditions. Russian Ophthalmol Child 2019; 1: 22-27.

19. Markelova S. The role of printed and electronic publications in development of vision disorders. Fund Clin Med 2019; 4: 97-104.

20. Tumanova AL. Monitoring studies of dynamic health indicators in students. Int J Appl Basic Res 2013; 8-3: 24-26.

21. Hinkle DE, Wiersma W, Jurs SG. Applied statistics for the behavioral sciences. 5th ed. Houghton Mifflin, Boston 2003.

22. WMA declaration of Helsinki - ethical principles for medical research involving human subjects. Available from: file:///C:/Users/Andriej\%20Szpakow/Downloads/wma-declaration-of-helsinki-ethical-principles-for-medical-research-involving-human-subjects. pdf (cited 19 March 2020).

23. Denecke K, Bamidis P, Bond C, et al. Ethical issues of social media usage in healthcare. Yearb Med Inform 2015; 10: 137-147.

24. Ushakov IB, Popov VI, Petrova TN, et al. Studies of students' health as a result of interaction between medical biologic, ecologic and social hygienic risk factors. Russian J Occup Health Industrial Ecology 2017; 4: 33-36.

25. Kuchma VR, Suhareva LM, Rapoport IK, et al. Population health of children, risks to health and sanitary and epidemiological wellbeing of students: problems, ways of solution and technology of the activity. Hygiene and Sanitation 2017; 96: 990-995.

26. Gök T. The positive and negative effects of digital technologies on students' learning. EPESS 2015; 2: 173-177.

27. Blehm C, Vishnu S, Khattak A, et al. Computer vision syndrome: a review. Surv Ophthalmol 2005; 50: 253-262.

28. Bogdănici CM, Săndulache DE, Corina Andreea Nechita CA. Eyesight quality and computer vision syndrome. Rom J Ophthalmol 2017; 61: $112-116$

29. Mutti D, Zadnik K. Is computer use a risk factor for myopia? J Am Optom Assoc 1996; 67: 521-530.

30. Chassiakos YLR, Radesky J, Christakis D, et al. Children and adolescents and digital media. J Am Acad Pediatrics 2016; 138: 3-6. 